\title{
WALTER BENJAMIN E O MARXISMO ${ }^{1}$
}

Michel Löwy²

- RESUMO: O presente artigo visa analisar as relações entre Benjamin e o marxismo, sem, entretanto, esquecer que o pensamento do filósofo comporta, ao mesmo tempo, uma vertente marxista e outra messiânica.

- PALAVRAS-CHAVE: Benjamin; marxismo; antideterminismo; messianismo; teologia.

Benjamin ocupa um lugar único na história do pensamento marxista moderno: é o primeiro partidário do materialismo histórico a romper radicalmente com a ideologia do progresso. Por conseguinte, seu marxismo possui uma qualidade particular que o separa das formas dominantes e oficiais, conferindo-lhe uma formidável superioridade metodológica.

Esta particularidade não deixa de estar relacionada com sua capacidade de incorporar, ao núcleo do corpo teórico do marxismo revolucionário, elementos da crítica romântica da civilização, assim como da tradição messiânica judaica. Estes dois elementos estão presentes nos seus primeiros escritos (não-marxistas), particularmente em $A$ vida dos estudantes (1915), onde já rejeita "uma concepção da história [que] só distingue o ritmo dos homens e das épocas que correm rápida ou lentamente na esteira do progresso", caracterizada pela "ausência de nexo, a falta de precisão e de rigor que ela coloca em relação ao presente" e a que opõe "a imagem utópica", como "o reino messiânico ou a Revolução Francesa" (Bolle, 1986, p. 151).

A primeira referência de Benjamin ao comunismo aparece em 1921 em sua Crítica da violência: "Aos pacifistas se opõem bolchevistas e sindicalistas. Eles fizeram uma crítica arrasadora, no todo acertada, dos parlamentos atuais" (p. 167). Esse elo entre

1. Artigo publicado em Critique Communiste, n. 134, verão de 1993. Tradução de Isabel Maria Loureiro. A identificação das referências no original alemão e nas correspondentes versões brasileiras, assim como a tradução de várias passagens inexistentes em português foi feita por Ernani Chaves, a quem muito agradeço.

2. Pesquisador do CNRS, Paris. 
comunismo e anarquismo será um aspecto importante de sua evolução política; seu marxismo adquirirá, em grande medida, uma coloração libertária.

Mas é somente após 1924, quando lê Histónia e consciência de classe, de Lukács, e quando descobre o comunismo prático pelos olhos de Asya Lacis, que o marxismo vai tornar-se um elemento chave de sua concepção do mundo. Em 1929, Benjamin refere-se sempre ao ensaio de Lukács como a um dos poucos livros que permanecem vivos e atuais:

A obra mais perfeita da literatura marxista. Sua singularidade funda-se na segurança com a qual compreendeu, na situação crítica da filosofia, a situação crítica da luta de classes, e na revolução concreta, que está em cima da hora, a pré-condição absoluta, até mesmo a absoluta completude e a última palavra do conhecimento teórico. A polêmica contra esta obra, publicada pelas instâncias do Partido Comunista, sob a direção de Deborin, confirma, a seu modo, sua importância.(1991b, p. 171)

Este comentário ilustra a independência de espírito de Benjamin a respeito da versão "oficial" do marxismo soviético, inclusive num momento em que encarava seriamente a possibilidade de unir-se ao movimento comunista. Numa carta a Scholem (setembro de 1924), evoca o conflito interior entre seu "nilismo" e a dialética hegeliana de Lukács (Benjamin, 1978, p. 355); ${ }^{3}$ entretanto, é atraído pela prática política comunista em virtude de sua "atitude que vincula" (verbindliche Haltung); o que lhe interessa no livro de Lukács é a unidade entre a teoria e a prática, que constitui o núcleo central da obra e lhe confere sua imensa superioridade; qualquer outro método não passa de "demagogia e fraseologia burguesa".

A primeira obra em que se sente a influência do marxismo é Rua de mão única, escrita de 1923 a 1925 e publicada em 1928 (Benjamin, 1987). A mudança no seu pensamento é ilustrada pela comparação entre a primeira versão do manuscrito, redigida em 1923, e a última, datada de 1925.

Na primeira versão, é dito da vítima da miséria: "Ela deve então manter seus sentidos vigilantes para cada humilhação que lhe é infligida e mantê-los disciplinados até que seu sofrimento tenha trilhado não mais a ladeirenta rua do ódio, mas o caminho ascensional da prece". (1991c, p. 923). A versão "marxista" de 1925 repete quase a mesma coisa, mas o fim é diferente: "até que seu sofrimento tenha trilhado não mais a ladeirenta rua da amargura, mas o caminho ascensional da revolta" (1987, p. 22). Nesta única frase encontra-se concentrada a surpreendente transformação de suas idéias políticas no curso desses dois anos.

Sua precedente crítica do progresso, neo-romântica, é doravante carregada de um conteúdo marxista revolucionário, como na famosa passagem "Alarme de incêndio":

3. Ver Walter Benjamin, 1989. Organização e notas de Gershom Scholem e Theodor Adorno. 
E se a eliminação da burguesia não estiver efetivada até um momento quase calculável do desenvolvimento econômico e técnico (a inflação e a guerra de gases o assinalam), tudo está perdido. Antes que a centelha chegue à dinamite, é preciso que o pavio que queima seja cortado. (1987, p. 46)

Será o proletariado capaz de cumprir essa tarefa histórica? "A permanência ou o fim de um desenvolvimento cultural de três milênios são decididos pela resposta a isso" (1987, p. 45).

Contrariamente ao marxismo evolucionista vulgar, Benjamin não concebe a revolução proletária como o resultado "natural" ou "inevitável" do progresso econômico e técnico, mas como a interrupção de uma evolução conduzindo à catástrofe.

Esse ponto nodal explica por que seu marxismo possui um espírito pessimista - um pessimismo revolucionário que nada tem a ver com a resignação fatalista. No seu artigo sobre o surrealismo, de 1929 - no qual tenta novamente reconciliar anarquismo e marxismo -, ele define o comunismo como a organização do pessimismo, acrescentando ironicamente ter "uma confiança ilimitada apenas na indústria bélica e no aperfeiçoamento da força aérea para fins pacíficos (Bolle, 1986, p. 114). ${ }^{4}$ Essas duas instituições não tardariam a demonstrar, indo além dos prognósticos mais pessimistas de Benjamin, o uso sinistro que pode ser feito da tecnologia moderna.

Entretanto, após 1933, inicia-se um curto período no decorrer do qual Benjamin parece tentado a adotar certos elementos do marxismo soviético e, em particular, sua concepção "progressista" das forças produtivas. Os artigos escritos entre 1933-1935, em que se pode encontrar uma apreciação muito positiva do progresso técnico particularmente em "Experiência e pobreza" (1933), "O autor como produtor" (1934), "A obra de arte na época de sua reprodutibilidade técnica" $(1935)^{5}$ - são também os que contêm um apoio acrítico ao modelo soviético do socialismo, cuja ideologia, nessa época (a do plano quinquenal), era feita com o marxismo mais industrialista e produtivista possível. No entanto, não se deve esquecer que esses documentos são um pouco ambíguos. Em "Experiência e pobreza", ele celebra o fim da cultura como uma tábula rasa salutar, mas a imagem utilizada para definir a nova civilização - sóbria e fria como o gelo e o metal - é assustadora: "uma nova barbárie". E a respeito do artigo sobre o trabalho de criação artística, Scholem (1989, p. 206) já frisou a contradição entre a primeira e a segunda parte (a celebração do cinema).

Esses artigos são considerados os textos mais "marxistas" escritos por Benjamin; a meu ver, são apenas os mais próximos da concepção estabelecida do marxismo aceita pela maioria dos teóricos "ortodoxos" dos movimentos comunista ou social-democrata. Os ensaios de Benjamin de 1925 a 1933 e, mais tarde, de 1936 a 1940, também são marxistas, mas pertencem a uma variedade original e "heterodoxa" de materia-

\footnotetext{
4. Benjamin, "O surrealismo. O último instantâneo da inteligência européia".

5. Textos publicados em Benjamin, Magia e técnica, arte e política. Ensaios sobre literatura e história da cultura. São Paulo: Brasiliense, 1986.
} 
lismo histórico, entrando em conflito com os padrões dominantes, em virtude de sua concepção não-evolucionista e não-progressista da história.

O fim dessa tentativa de apoiar certos aspectos do marxismo soviético parece coincidir com os processos de Moscou de 1936, acolhidos com perplexidade por Benjamin. No decorrer dos anos 1937-1940, Benjamin torna-se cada vez mais crítico em relação à política soviética, até que ajusta contas com o marxismo do Komintern nas Teses - "sobre o conceito de história", de 1940 (trad. inédita mimeografada).

O artigo sobre Fuchs, de 1937, é uma crítica severa ao marxismo social-democrata, unido ao positivismo, ao evolucionismo darwinista e ao culto do "progresso":

Ele [o positivismo] só podia reconhecer na evolução da técnica o progresso da ciência natural, e não a regressão da sociedade ... As energias que a técnica desenvolve para além desse limiar são destruidoras. Elas exigem em primeiro lugar a técnica da guerra e sua preparação pela imprensa. (Benjamin, 1991a, p. 474-5)6

Benjamin opõe sua perspectiva pessimista-revolucionária ao otimismo superficial dos epígonos marxistas modernos, e refere-se aos prognósticos de Marx e Engels quanto ao desenvolvimento bárbaro do capitalismo. A ruptura de Benjamin com a perspectiva "materialista-progressista" nos anos 1933-1935 não constitui uma ruptura com o marxismo enquanto tal. Os ensaios de 1936-1940 também são marxistas, mas constituem uma interpretação nova e criativa do materialismo histórico, alimentada pela cultura romântica e a teologia judaica, e radicalmente diferente da doutrina da II ${ }^{\mathrm{a}}$ e da III Internacional.

Evidentemente, o objetivo de Benjamin é aprofundar e radicalizar a oposição entre o marxismo e a ideologia burguesa, aguçar seu potencial revolucionário e elevar seu conteúdo crítico. É precisamente o objetivo do projeto da Obra das passagens: "Pode-se considerar também como fim perseguido metodologicamente nesse trabalho a possibilidade de um materialismo histórico que tenha aniquilado nele mesmo a idéia de progresso. É justamente opondo-se aos hábitos do pensamento burguês que 0 materialismo histórico encontra suas fontes". Um programa assim não se lançava a qualquer tipo de "revisão", mas antes - como Korsch (1924) tentara fazer no seu próprio livro (uma das maiores fontes de Benjamin) - a um retorno ao próprio Marx.

Uma das análises mais penetrantes de Benjamin, a respeito da perda de experiência dos trabalhadores e da sua transformação em autômatos, presente na Obra das passagens e no ensaio sobre Baudelaire, inspira-se diretamente em Marx e Engels.

Cita a seguinte passagem de $O$ Capital: os trabalhadores são obrigados a coordenar "seu próprio movimento ao movimento uniforme, constante, de um autômato" (Benjamin, 1989, p. 125). ${ }^{7}$ Benjamin (1991d, p. 162) conclui daí que os trabalha-

6. Benjamin, "Eduardo Fuchs, der Sammler und der Historiker".

7. A citação de Benjamin está em "Sobre alguns temas em Baudelaire". In: Obras escolhidas III. São Paulo: Brasiliense, 1989, p. 125. A edição de O Capital utilizada por Benjamin é a organizada por Korsch (Berlim, 1932) 
dores vivem numa espécie de inferno, pois sua vida é uma eterna repetição. Citando Engels, compara a condição dos trabalhadores à prisão de Sísifo. ${ }^{8}$

Evidentemente, a leitura de Marx por Benjamin é seletiva: ele escolhe as passagens que podem ser conciliadas com a teoria do "trabalho apaixonado" de Fourier e interpreta o fetichismo da mercadoria à maneira de Adorno (1964): "No objeto de consumo, o traço de sua produção deve ser esquecido. A essência fantasmagórica do fetichismo da mercadoria é o 'ocultamento do trabalho'."

Benjamin tinha consciência de que essa leitura do marxismo mergulhava suas raízes na crítica romântica da civilização industrial. Mas estava convencido de que o próprio Marx tinha encontrado sua inspiração nas mesmas fontes, encontrando apoio, nesse sentido, na obra de Korsch: "Muito corretamente, e não sem nos fazer pensar em de Maistre e de Bonald, Korsch diz o seguinte:

Assim também ... na teoria do movimento operário moderno ... foi introduzida uma parte daquela "desilusão" que ... após a grande Revolução Francesa, foi proclamada pelos primeiros teóricos da contra-revolução e, em seguida, pelos românticos alemães, e que, especialmente através de Hegel, exerceu forte influência sobre Marx (1991d, p. 820)

Segundo Habermas, existe uma contradição entre a filosofia da história de Benjamin e o materialismo histórico. Em sua opinião, o erro de Benjamin foi impor ao materialismo histórico - "que supõe progressos não só na dimensão das forças produtivas como também na da dominação" - "uma concepção anti-evolucionista da História", foi tê-lo recoberto com "um capuz de monge" (Habermas, 1980, p. 195).

Nos nossos dias, uma interpretação dialética e não-evolucionista da história, levando em conta ao mesmo tempo o progresso e as regressões (como fizeram Benjamin e a Escola de Frankfurt), pode fundar-se em vários escritos de Marx. Entretanto, é verdade que ela entra em conflito com as interpretações dominantes do materialismo histórico desenvolvidas no decorrer do século XX. O que Habermas pensa ser um erro está precisamente na origem do valor singular do marxismo de Benjamin e de sua superioridade sobre o "evolucionismo progressista", está em compreender um século caracterizado pela imbricação da modernidade e da barbárie (como em Auschwitz ou Hiroshima).

A formulação mais radical dessa interpretação anti-evolucionista do materialismo histórico encontra-se evidentemente nas Teses - "Sobre o conceito de história", onde a ideologia do progresso - inclusive no seio do movimento comunista - é criticada nos seus fundamentos filosóficos (uma concepção linear e vazia do tempo).

Esta crítica é baseada numa concepção messiânica do tempo. Evidentemente, a questão das relações entre o marxismo e o messianismo nos últimos escritos de Benjamin é muito controversa. Alguns vêem aí uma secularização, outros, ao contrário (como Gerhard Kaiser), uma "teologização do marxismo" (Cf. Bulthaup, 1975, p. 43).

8. Benjamin cita o trecho de A situaçãa da classe trabalhadora na Inglaterra a partir da citação feita por Marx desse mesmo texto em O Capital, I, p. 388 (Hamburgo, 1922). 
No decorrer das duras polêmicas dos anos sessenta, alguns enfatizaram a dimensão religiosa, outros o materialismo marxista. O próprio Benjamin considerava seu pensamento como tendo um "rosto de Janus" (Cf. Scholem, 1989, p. 200), mas os críticos apegaram-se a uma única face, ignorando a outra. Para ultrapassar essas polêmicas, não é inútil lembrar que o deus romano tinha dois rostos, mas uma única cabeça: os dois rostos de Benjamin são a expressão de um só e único pensamento que comporta, ao mesmo tempo, uma vertente marxista e uma vertente messiânica.

Tomemos como exemplo a Tese $\mathrm{n}^{\circ}$ 1, a famosa alegoria do autômato jogador de xadrez:

Consta, ao que se sabe, que existiu um autômato, construído de tal maneira que ele, a cada jogada de um enxadrista, respondia com uma contrajogada que lhe assegurava a vitória da partida. Diante do tabuleiro que repousava sobre uma mesa espaçosa sentava-se uma boneca em trajes turcos com um narguilé à boca. Um sistema de espelhos despertava a ilusão de que esta mesa era transparente de todos os lados. Na verdade, um anão corcunda, mestre no jogo de xadrez, estava sentado dentro dela e conduzia por fios a mão da boneca. Pode-se representar na filosofia um equivalente desta aparelhagem. A boneca que se chama 'materialismo histórico' deve ganhar sempre. Ela pode medir-se, sem mais, com qualquer adversário, desde que tome a seu serviço a teologia, que, hoje, sabidamente, é pequena e feia e que, de toda maneira, não deve se deixar ver (Benjamin, mimeo).

Dois temas se amalgamam nesta alegoria: uma crítica da versão do marxismo que compreende a história como uma mecânica que conduz automaticamente ao triunfo do socialismo; uma utilização herética da força explosiva, messiânica, revolucionária, do materialismo histórico, reduzido a um automatismo miserável pelos seus epígonos.

No seu célebre ensaio, Heinz-Dieter Kittsteiner propõe interpretar a Tese $n^{\circ} 1$ no interior da diferença funcional entre o anão e a marionete: "O materialista histórico defronta-se com o presente como marxista e com o passado como teólogo das reminiscências" (Bulthaup, 1975, p. 37). ${ }^{9}$

Entretanto, esta divisão do trabalho não corresponde às idéias de Benjamin: uma leitura atenta de suas teses mostra que ele considera o marxismo necessário à compreensão da luta de classes no passado, e a teologia para agir no presente e no futuro.

A articulação entre a teologia e o materialismo resolve-se de maneira particularmente paradoxal na alegoria: no início, o anão teólogo é apresentado como senhor do autômato, que ele utiliza como uma espécie de instrumento; contudo, no final da Tese $\mathrm{n}^{\circ} 1$, fica claro que $\mathrm{o}$ anão está a serviço do autômato. O que significa esta inversão? Parece que Benjamin quis mostrar sua complementaridade dialética: teologia e marxismo são senhor e servidor recíprocos, precisam um do outro.

9. "Die Geschichtsphilosophischen Thesen". In: Bulthaup. Op. cit., p. 37. (Originalmente em Alternative, 56/57, out.dez. 1967). 
É necessário levar em conta seriamente a idéia segundo a qual a teologia está a serviço do materialismo histórico - uma fórmula que inverte a tradicional definição escolástica da filosofia como "ancilla theologiae". A teologia, como memória, redenção, salvação, não é, para Benjamin, um objetivo em si, uma contemplação etérea da verdade divina. Ela está a serviço do combate dos oprimidos.

Algumas décadas após a morte de Benjamin, a idéia de uma teologia a serviço dos pobres no combate pela sua libertação, uma teologia estreitamente articulada com as análises marxistas, retorna, mas num contexto cultural e histórico muito diferente: o do cristianismo latino-americano. Mas há sem dúvida uma afinidade secreta entre Benjamin e a Teologia da Libertação.

LÖWY, M. Walter Benjamin and Marxism. Trans/Form/Ação, São Paulo, v. 17, p. 7-13, 1994.

- ABSTRACT: This article analyses the relationship between Benjamin and Marxism, without however failing to recognize that the philosopher's thought has at the same time two sides: one Marxist and another messianic.

- KEYWORDS: Benjamin; Marxism; antideterminism; messianism; theology.

\section{Referências bibliográficas}

1 ADORNO, T. W. Essai sur Wagner. Paris: Gallimard, 1964.

2 BENJAMIN, W. Gesammelte Schriften II. Frankfurt am Main: Suhrkamp, 1991a.

3 _. Gesammelte Schriften III. Frankfurt am Main: Suhrkamp, 1991b.

4 _. Gesammelte Schriften IV-2. Frankfurt am Main: Suhrkamp, 1991c.

5 _. Gesammelte Schriften V. Frankfurt am Main: Suhrkamp, 1991d.

6 S Sobre o conceito de histónia. Trad. de J. M. Gagnebin e M. Müller. (Mimeogr.).

7 B Briefe I. Frankfurt/Main: Suhrkamp, 1978.

8 - Obras escolhidas II. São Paulo: Brasiliense, 1987.

9 Obras escolhidas III. São Paulo: Brasiliense, 1989.

10 BOLLE, W. (Org.). Walter Benjamin. Documentos da cultura. Documentos da barbárie. São Paulo: Cultrix/EDUSP, 1986. (Escritos escolhidos).

11 BULthauP, P. (Org.). Matenialien zu Benjamins Thesen über den Begriff der Geschichte. Frankfurt am Main: Suhrkamp, 1975.

12 ROUANET, S. P., FREITAG, B. (Org.). Habermas. São Paulo: Ática, 1980. (Grandes Cientistas Sociais).

13 KORSCH, K. Marxisme et philosophie. Paris: Editions de Minuit, 1964.

14 SCHOLEM, G. Walter Benjamin - história de uma amizade. São Paulo: Perspectiva, 1989. 